\title{
Instituto de Biociências
}

ERASMO GARCIA MENDES

$\mathrm{A}$ ntes da criação da seçáo de História Natural na Faculdade de Filosofia, Ciências e Letras da Universidade de São Paulo, o ensino de biologia e geologia levando à graduaçáo nessas matérias não se achava sistematizado em nível superior no Brasil. Não obstante, notáveis biólogos e geólogos surgiram no país, oriundos de faculdades profissionalizantes (medicina, agronomia, engenharia etc.), nas quais elementos de biologia e geologia eram ministrados complementarmente às disciplinas formativas. Egressos de tais faculdades não raro deixaram de se profissionalizar e, nelas próprias ou em institutos oficiais - ou não - de pesquisa, tornaram-se eminentes especialistas. Não foram raros também os que, sem qualquer formaçáo universitária, autodidaticamente, trabalhando nessas instituiçōes, tornaram-se pesquisadores, granjeando grande reputaçăo. Nada impede que esses modos de formar o biólogo ou geólogo continuem funcionando, mas parece claro que os estudos de biologia e geologia em institutos universitários especializados passaram a constituir a via rápida e efetiva da consecução de objetivos.

No decreto de criaçáo da Universidade de São Paulo, na parte concernente à Faculdade de Filosofia, Ciências e Letras, constaram do Título II, Capítulo II disciplinas biológicas e geologicas como formadoras da seção de Cilncias Naturatis, que sob essa denominação começou a funcionar em 1935. Essa seçáo, por impropriedade do nome, acabou convertendo-se em Historia Natural e, como tal, continuou até 1957. Compunha-se dos seguintes departamentos: Mineralogia e Petrografia, Geologia e Paleontologia, Biologia Geral, Zoologia, Botânica e Fisiologia Geral e Animal. Nesse ano, a seçáo foi desmembrada em Ciencias Biológicas e Ciencias Geológicas, permanecendo no âmbito da Faculdade de Filosofia até a Reforma Universitária em 1970.

Com essa reforma, a Faculdade de Filosofia, Ciências e Letras cedeu várias de suas seçóes para a constituiçăo de novas unidades de ensino, transformando-se em Faculdade de Filosofia, Letras e Ciências Humanas. Desse modo surgiu o atual Instituto de Biociências, oriundo da seçáo de Ciências Biológicas da velha Faculdade de Filosofia. Dos departamentos da antiga seção, três mantiveram o mesmo nome: o de Biologia Geral, o de Zoologia e o de Botânica; o Departamento de 
Fisiologia Geral e Animal passou a denominar-se simplesmente Fisiologia Geral e foi criado um novo departamento, o de Ecologia Geral.

A Reforma ocasionou também modificaçóes na estrutura curricular de disciplinas. Assim, o Departamento de Biologia cedeu ao Departamento de Histologia do Instituto de Ciências Biomédicas as disciplinas Histologia e Embriologia, conservando as de Citologia, Genética e Evoluçáo; a Bioquímica passou a ser ensinada no Instituto de Química, e a Estatística, a Matemática e a Física (disciplinas complementares) nos Institutos também criados pela Reforma para esses fins. $O$ vínculo residual com as ciências geológicas da antiga seção de mesmo nome, na Faculdade de Filosofia, hoje o Instituto de Geociências, ficou constituído pelas disciplinas Geologia Geral e Paleontologia, indispensáveis à formação do biólogo.

Até a reforma, os departamentos eram chefiados por professores catedráticos. No caso das biociências, os primeiros catedráticos foram André Dreyfus (Biologia Geral), Felix Rawitscher (Botânica), Ernesto Marcus (Zoologia) e Paulo Sawaya (Fisiologia Geral e Animal). Inicialmente, os departamentos da seção de História Natural da Faculdade de Filosofia, Ciências e Letras estiveram instalados em dependências da Faculdade de Medicina, na avenida Dr. Arnaldo. Em 1938 eles foram transferidos para o prédio situado na esquina da alameda Glete com a rua Guaianases (antiga residência do industrial Jorge Street). A partir de 1955 , foram aos poucos sendo mudados para prédios próprios na Cidade Universitária. Atualmente, os Departamentos de Biologia e Botânica ocupam o Edificio André Dreyfus, que tem, em frente, outro prédio destinado a aulas. Os Departamentos de Zoologia e Fisiologia Geral, bem como o Departamento de Ecologia Geral, estáo alocados no Edifício Ernesto Marcus, que abriga também a Biblioteca do Instituto de Biociências. Essa biblioteca será transferida em breve para um novo prédio, em fins de construção entre os Edifícios André Dreyfus e Ernesto Marcus. Esse novo prédio abrigará também salas de aulas teóricas e práticas de todos os departamentos. Todo esse conjunto arquitetônico está situado na parte alta da Cidade Universitária, nas vizinhanças da Reserva Florestal e do Viveiro de Plantas. Outro prédio foi também construído para alojar um restaurante para servidores e alunos, na parte superior e, na inferior, o Centro Acadêmico do Instituto. O Departamento de Botânica, no espaço livre, atrás do Edifício André Dreyfus, mantém um grande jardim para fins de ensino e pesquisa. O Departamento de Ecologia possui um apiário, ao redor de um pequeno prédio, destinado à investigaçáo. No hall do andar térreo do Edifício Ernesto Marcus há um pequeno museu de Zoologia, franqueado ao público. $O$ Departamento de Fisiologia Geral construiu seu biotério em espaço 
livre na vizinhança imediata deste último edifício. $O$ Departamento de Biologia mantém, isolado em um prédio nas imediaçōes do Edifício André Dreyfus, um laboratório para o estudo dos efeitos das radiações em processos biológicos.

A seguir, estão discriminadas as principais linhas de pesquisa atuais do Instituto de Biociências da Universidade de Sáo Paulo.

Erasmo Garcia Mendes é professor emérito da USP e integma a Mesa Editorial da revista Estrudos Avasugados. 